\title{
THE PHARMACOLOGICAL ACTIONS OF POLYMETHYLENE BISTRIMETHYLAMMONIUM SALTS
}

\author{
BY \\ W. D. M. PATON AND ELEANOR J. ZAIMIS* \\ From the National Institute for Medical Research, London
}

(Received October 13, 1949)

Since the classical work of Crum Brown and Fraser, the curariform action of many onium salts has been recognized, and other activities exerted by these compounds have been described, such as those commonly called nicotine-like or muscarine-like. In the present paper an account is given of the actions of members of a polymethylene bistrimethylammonium series, whose general formula is $\left(\mathrm{CH}_{3}\right)_{3} \mathrm{~N}+\left(\mathrm{CH}_{2}\right)_{n} \mathrm{~N}+\left(\mathrm{CH}_{3}\right)_{3} .2 \mathrm{I}$. The compounds will be referred to by the value of $n$; thus $\mathrm{C10}$ is the decane derivative, where $n=10$. Our attention was drawn to the series during a test of the power of the octamethylene compound to liberate histamine. After the injection of a small dose into a cat, there was no depressor response, such as histamine-liberators cause (MacIntosh and Paton, 1949); on the contrary, the blood pressure rose. This rise was evidently asphyxial, since the respiration had simultaneously ceased; but there were no gasps or convulsive movements such as usually accompany asphyxia, and the sequence of events suggested some form of neuromuscular block.

This series has also been independently studied by Barlow and Ing, with whom a simultaneous preliminary report was arranged (Barlow and Ing, 1948a ; Paton and Zaimis, 1948a), and who have now reported their results more fully (Barlow and Ing, 1948b).

Following a further note (Paton and Zaimis, 1948b), preliminary clinical trials of the decane derivative as a substitute for $d$-tubocurarine chloride in anaesthesia and convulsion therapy were instituted. These have proved successful, and the name "decamethonium iodide" has been approved by the. British Pharmacopoeia Commission as the official name for the compound.

Our investigations of the pharmacological actions of these compounds have been chiefly directed to studying their activity in blocking neuromuscular transmission. Particular attention

* British Council scholar. has been paid also to describing how the pharmacological activity varies with the length of the polymethylene chain. Later papers will report more fully experiments on other pharmacological actions.

\section{MeTHODS}

\section{Effects on neuromuscular transmission}

Cats anaesthetized with chloralose $(80 \mathrm{mg} . / \mathrm{kg}$.$) ,$ after induction with ether, were used in most of the experiments. For recording the tension of muscle twitch, tibialis anterior was prepared; the preparation was mounted on the Brown-Schuster myograph stand, and an isometric steel spring myograph was used for recording on the smoked drum. The muscle was excited either by slightly supra-maximal shocks to the sciatic nerve through shielded silver electrodes, or directly by induction coil break shocks. The nerve was tied centrally, above the point of stimulation and above the point of entry of its blood supply. Injections were made either intravenously through a cannula tied into the femoral or jugular vein, or by the method of close arterial injection into the anterior tibial artery (Brown, 1938a). A few animals were anaesthetized with pentothal infused at a rate of $0.3-0.5 \mathrm{mg}$. $/ \mathrm{min}$., or with ether from an "Oxford vaporizer" adapted for animal use, using 6-7 per cent ether.

For experiments on unanaesthetized animals, injections of volumes of 0.01 c.c. $/ \mathrm{g}$. were made into the tail vein of mice (white, male, weight $18-20 \mathrm{~g}$.) and rats (male, weight 100-150 g.). (The effective dose was that which prevented the animal righting itself when placed on its back.) Rabbits (male, weight 1.5-2 kg.). were used for the continuous infusion headdrop method (Dutta and MacIntosh, 1949), or received rapid intravenous injections in the marginal ear vein. Cats, monkeys (Macaca mulatta), and a baboon (Papio anubis) received injections in the saphenous vein. Frogs were tested as described by King (1935).

\section{Other methods}

In cats anaesthetized with chloralose, the contraction of the nictitating membrane was recorded on the smoked drum. The membrane was excited to contraction by maximal stimuli applied to the peripheral 

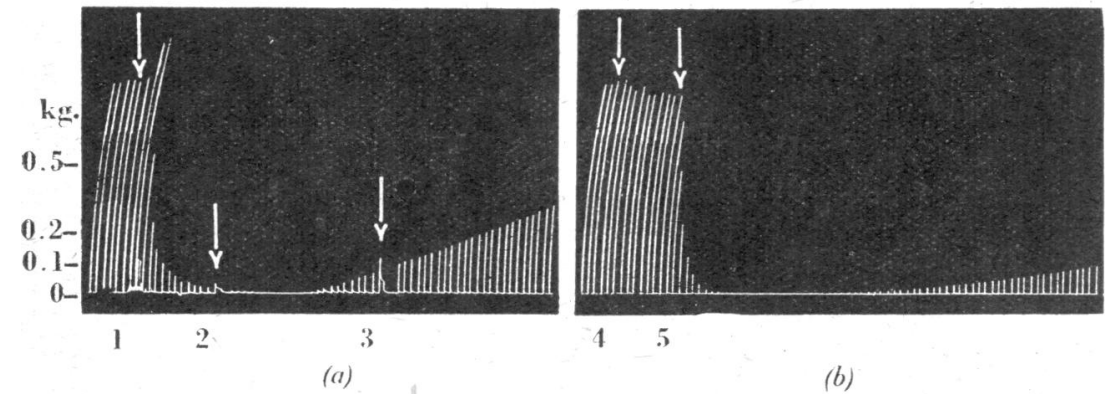

Fig. 1 (a).-Cat, chloralose, $3.7 \mathrm{~kg}$. Record of contractions of tibialis excited by supramaximal shocks to the sciatic nerve every $10 \mathrm{sec}$. At $1,0.12 \mathrm{mg}$. C10 intravenous injection. At 2 and 3, tetanic stimulus to motor nerve, $50 / \mathrm{sec}$. (b) Same experiment, $36 \mathrm{~min}$. later. $d$-Tubocurarine chloride $0.3 \mathrm{mg}$. intravenously $5 \mathrm{~min}$. previously. At $4,0.12 \mathrm{mg}$. C10 i.v. At $5,0.24 \mathrm{mg}$. C10 i.v.

\section{- Results}

Neuromuscular block Action of $\mathrm{ClO}$ on the neuromuscular junction

The most notable activity of this series is that possessed by the higher members in causing neuromuscular block. Fig. $1 a$ shows the effect of the intravenous injection of a small dose of $\mathrm{Cl0}$ (the most active compound in this respect)

stump of the cervical sympathetic, cut and separated from the vagus in the neck; a rate of stimulation of 10 per sec. produced a well-sustained contraction. In other experiments, the isolated rabbit intestine preparation described by Feldberg and Lin (1949) was employed.

Muscarine-like action was tested on rabbit or guineapig- small intestine, suspended in Ringer solution containing magnesium chloride (0.004 g./100 c.c.) ; atropine sulphate $\left(10^{-7}\right)$ was used as an antagonist. The frog's rectus abdominis suspended in frog Ringer solution was employed in customary fashion to test for nicotine-like stimulation of skeletal muscle. The spinal cat was prepared as described by Barger and Dale (1910). for the cetection of pressor activity. Anticholinesterase activity was determined using a Warburg manometer, with rabbit's laked washed red cells and acetyl- $\beta$-methylcholine $(0.027 M)$ or rabbit plasma and benzoyl choline $(0.0055 M)$ as sources of and substrates for "true " or " pseudo" cholinesterase respectively. The substrate and inhibitor (if any) were placed in the sidearm of the Warburg bottle, so that shaking brought them into simultaneous contact with the enzyme; readings of the manometer were then made every 10 minutes for two hours. The surface tension of aqueous solutions of the compounds against air was measured with a De Nöuy tensionmeter. Values for the surface tension of glassdistilled water of $71.5-72.1$ dynes $/ \mathrm{cm}$. at $20-23^{\circ} \mathrm{C}$. were obtained.

Actions on the respiration were recorded at first by discharging the expirations of the animal (by means of light rubber valves) into a large glass vessel from which a fine adjustable leak was provided, and measuring the pressure within it by a sensitive tambour; later measurements were made with the respiration recorder described by Paton (1949a). Blood pressure was measured in the usual way, a cannula coated with silicone and filled with saline containing heparin being inserted into the carotid artery. We are much indebted to Dr. J. A. B. Gray for recording action potentials from the peroneal nerve and tibialis muscle for us in certain experiments. on the contractions of cat's tibialis muscle excited through its motor nerve. At first the tension is increased, and between the contractions fasciculations of the muscle can be seen. (The other muscles of the animal also exhibit these incoordinated contractions.) Then the twitch tension begins to diminish until, with this dose, the muscular contraction is almost completely abolished. When the muscle is completely paralysed to stimulation through its nerve, it is still capable of responding to direct stimulation (Fig. 2).

During the progress of such a paralysis the action potential of the motor nerve to tibialis remains

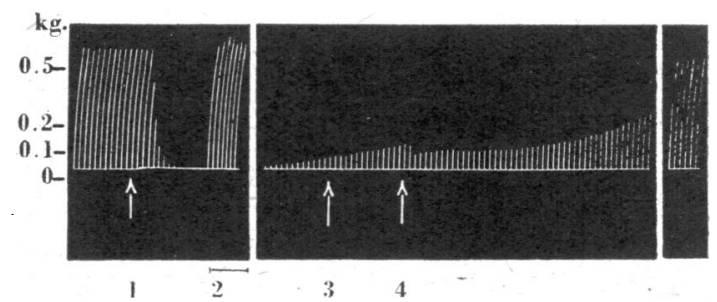

FIG. 2.-Cat, chloralose, $2.6 \mathrm{~kg}$. Tibialis; nerve shock every 10 sec. At arrow 1 , injection of $0.1 \mathrm{mg}$. C10 i.v. During 2, direct stimulation of muscle. At 3, $1 \mathrm{mg}$. atropine sulphate i.v. At $4,0.5 \mathrm{mg}$. neostigmine methylsulphate i.v.

completely unimpaired while the muscle action potential and twitch tension dwindle and disappear (Fig. 3A). The site of paralysis, therefore, must be placed in the end-plate region or in the terminal nerve endings.

One possible mechanism for such a paralysis might be abolition of the release of acetylcholine by the nerve endings, as has been described for procaine (Harvey, 1939) and suggested for atropine (Brown, 1937). We have found, however, that the effects of acetylcholine given by close arterial 

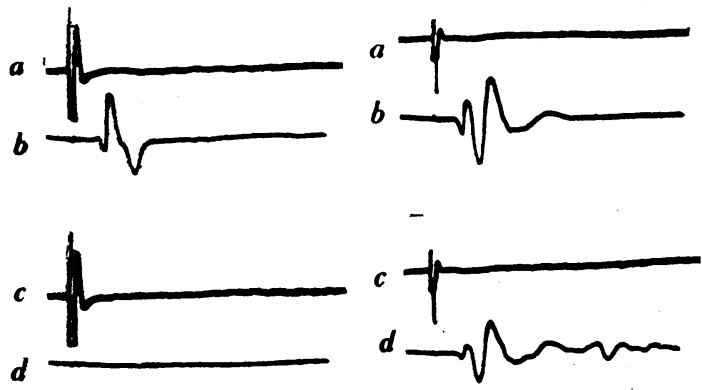

cat's plasma. The plasma was then tested on the cat's blood pressure. During the control period, there was no detectable depressor activity in the effluent ; stimulation of the motor nerve at a rate of 50 per sec. for $2 \mathrm{~min}$. caused the release of depressor material in a concentration equivalent to $5 \mathrm{~m} \mu \mathrm{g}$. acetylcholine per c.c. in the effluent, and the activity of this depressor material was abo.ished by the injection of $0.5 \mathrm{mg}$. atropine into the assay cat; this release was not prevented by adding $\mathrm{C} 10$ to the perfusion fluid to a concentration of $10^{-5}$.

The fasciculations and the potentiation of the twitch preceding neuromuscular block led us to test these compounds for anticholinesterase activity, since known anticholinesterases produce similar actions; and experiments in this connexion are described below which revealed that $\mathrm{C} 10$ and its neighbours possess some activity of this kind. (Later work (Zaimis, 1949) indicates, however, that if this anticholinesterase action plays a part in causing these effects, such a part is small.) The potentiation of the twitch may be considerable, and is best seen with smaller doses of $\mathrm{C10}$, such that the subsequent neuromuscular block is too small to obscure the potentiating process; Fig. 5 exemplifies such an experiment. With still smaller doses, a transient enhancement of the twitch tension may be the only evidence that $\mathrm{ClO}$ has been injected. It was necessary, therefore, to test whether the neuromuscular block might even be

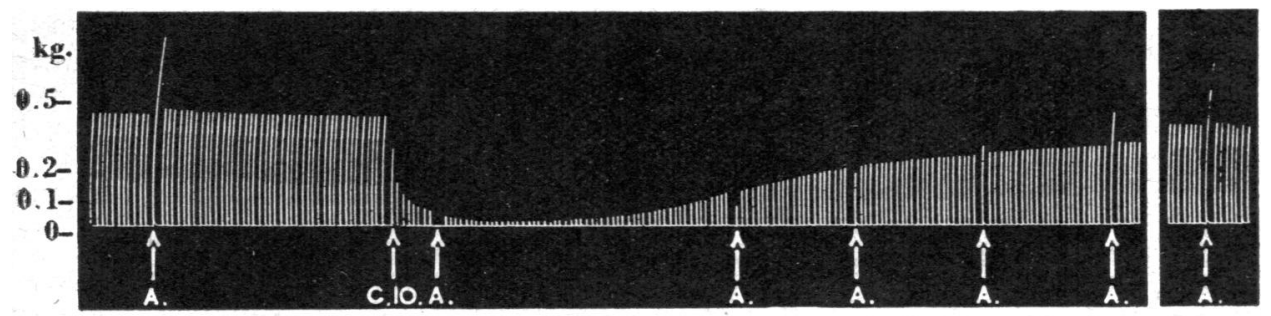

Fig. 4.-Cat, chloralose, $2.8 \mathrm{~kg}$. Tibialis: nerve shock every $10 \mathrm{sec}$. At A, injections of $5 \mu \mathrm{g}$. acetylcholine intra-arterially. At $\mathrm{C10}, 6 \mu \mathrm{g}$. C10 injected intra-arterially.

choline. Further, since these compounds are onium salts and do not have any local anaesthetic potency, there is no reason to expect a procainelike action. Since the block is completely reversible, there is no reason to suspect any action such as that due to botulinus toxin. Finally, the possibility that acetylcholine liberation might be depressed was tested directly in one experiment, in which the tibialis anterior muscle of a cat was dissected and perfused in isolation with eserinized a direct consequence of this anticholinesterase activity or not.

It is well known (Briscoe, 1936 ; Rosenblueth, Lindsley, and Morison, 1936) that eserine and other anticholinesterases can cause neuromuscular block, which has been ascribed to the presence of an excess of acetylcholine in the region of the neuromuscular junction. Under such conditions, however, the interposition of a tetanus, or the close arterial injection of acetylcholine 


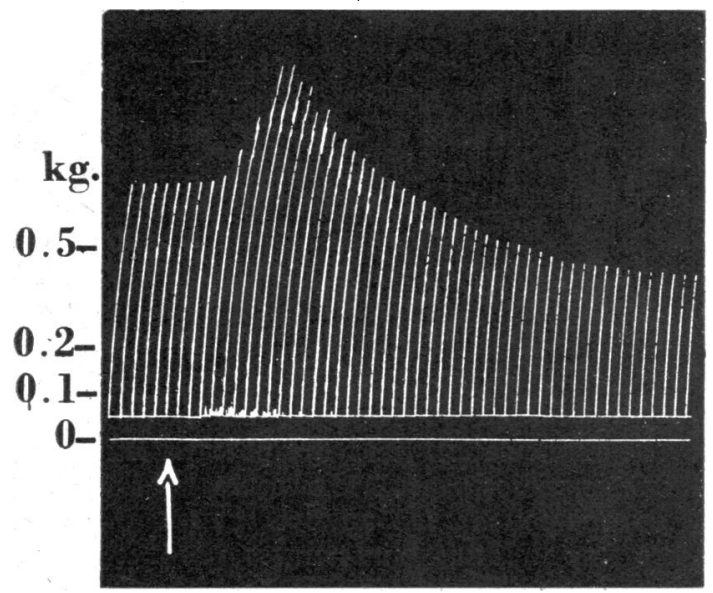

Fig. 5.-Cat, chloralose, 2.6 kg. Tibialis; nerve shocks every $10 \mathrm{sec}$. At arrow, $26 \mu \mathrm{g}$. C10 injected intravenously. The same dose was given 5 min. previously without any effect.

increases the block for the succeeding twitches (Bacq and Brown, 1937). We have used this phenomenon as a test of the nature of the block caused by $\mathrm{C10}$. Figs. $1 a$ and 4 show that there is no such depressant action by a tetanus or by injection of acetylcholine respectively on the twitch of a muscle partially paralysed with $\mathrm{C10}$; and it has been our constant experience that it would be hard to judge from the subsequent twitches that a tetanus had been applied or an injection made. (An apparent slight deepening of the block by acetylcholine in Fig. 9 was due to traces of $\mathrm{C} 10$ from the previous injection.) We have, moreover, never observed any relation between the rate of stimulation and the development of the block. Indeed, with a large dose of $\mathrm{C10}$ almost complete paralysis may occur after a single twitch. It is unlikely, therefore, that block due to $\mathrm{C10}$ is the result of the accumulation of acetylcholine at the end-plate. We do not wish, however, to underestimate the resemblance of some of our tracings to those resulting from injections of potent antiesterases (cf. Brown, Burns, and Feldberg, 1948), but it is possible that some of the latter produce a block otherwise than by their antiesterase action.

Our experiments in this connexion also showed that a muscle could still maintain a tetanic contraction at a height comparable with the twitch tension when partially paralysed with $\mathrm{C10}$. It is well known that the curarized muscle cannot do this ; our experiments on this important difference will be reported separately.

\section{Duration of action}

In the anaesthetized cat, the complete or nearly complete paralysis of tibialis that follows an intravenous dose of $30 \mu \mathrm{g} . / \mathrm{kg}$. of $\mathrm{C} 10$ usually begins to recover in 5-10 min., and recovery is complete in about $15 \mathrm{~min}$. Sometimes a twitch tension greater than the initial may be observed for a few minutes of the recovery (recapitulating the initial potentiation) before it returns to the original level. The presence of the drug, however, is still detectable for some time after the twitch tension has returned to normal, since the same dose given again less than $30 \mathrm{~min}$. after the first injection produces a greater effect. But with suitable spacing of doses, reproducible cycles of paralysis and complete recovery can be obtained for many hours, the only important change commonly observed being a diminution of the initial potentiation with the lapse of time. Our experience also suggests that $\mathrm{Cl0}$ has a rather steep dose-response curve ; thus, a dose of $20 \mu \mathrm{g}$. $/ \mathrm{kg}$. was sometimes without visible effect on twitch tension in an animal in which $30 \mu \mathrm{g} . / \mathrm{kg}$. produced temporarily a complete block. Corresponding to this, recovery from a C10 block, once it starts, is often rather rapid. $d$-Tubocurarine chloride differs significantly both in having a longer duration of action for a given peak action and in the slower waning of its effects.

Similar time relations are observed in unanaesthetized cats and in rabbits; both animals, after a dose of $\mathrm{C} 10$ sufficient to paralyse them fully, recover in about $10 \mathrm{~min}$., whereas $d$-tubocurarine chloride has a somewhat more prolonged action. In the monkey, however, the reverse is the case, and with equally effective doses $\mathrm{C10}$ has a duration of action about two to three times longer than that of $d$-tubocurarine chloride.

We have given $\mathrm{C10}$ by other routes in a few experiments. Administered by stomach tube, C10 is ineffective in cat and rabbit in doses less than fifty times the effective intravenous dose, but a dose of a hundred times may be lethal in an animal starved for $\mathbf{2 4}$ hours. The paralysis takes an hour or more to appear. By the subcutaneous route in the rabbit, about three times the intravenous dose is required for equal maximum effects; and the paralysis does not appear for about $10 \mathrm{~min}$. nor disappear entirely for about 2 hours. With intramuscular injections, slightly smaller doses are required, and the onset of paralysis is quicker. We have not, however, studied the relative doses required for equal peak effects by the various routes in any detail, and the values quoted are only approximate. 


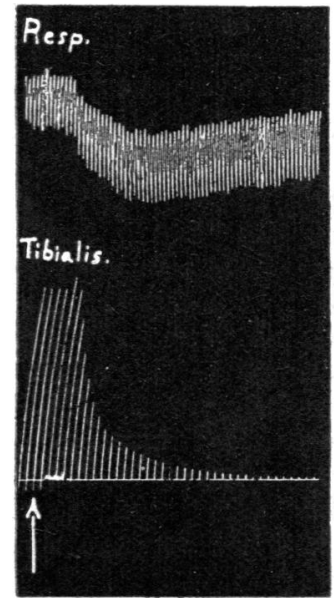

(a) (b)

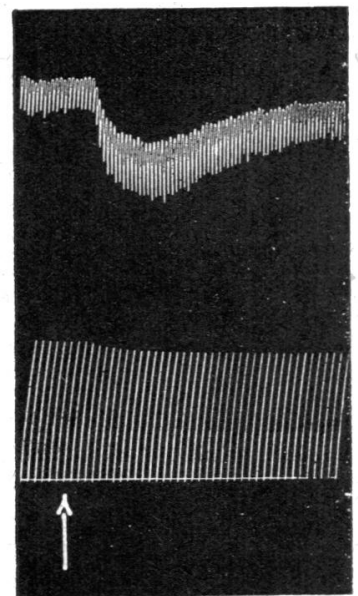

FIG. 6.-Cat, chloralose. Record of respiration and of tibialis; nerve shocks every 10 sec. (a) At arrow, $0.1 \mathrm{mg}$. C10 intravenously. (b) At arrow, $0.2 \mathrm{mg}$. $d$-tubocurarine chloride intravenously.

\section{Action on the respiration}

Fig. $6 a$ is the record of an experiment in which the respiratory volume was recorded simultaneously with the response of the tibialis muscle to single nerve shocks. Although the muscle response was almost completely abolished, the respiratory volume was but slightly affected. This has been a constant and striking experience. Sometimes, indeed, an increase in the respiratory minute

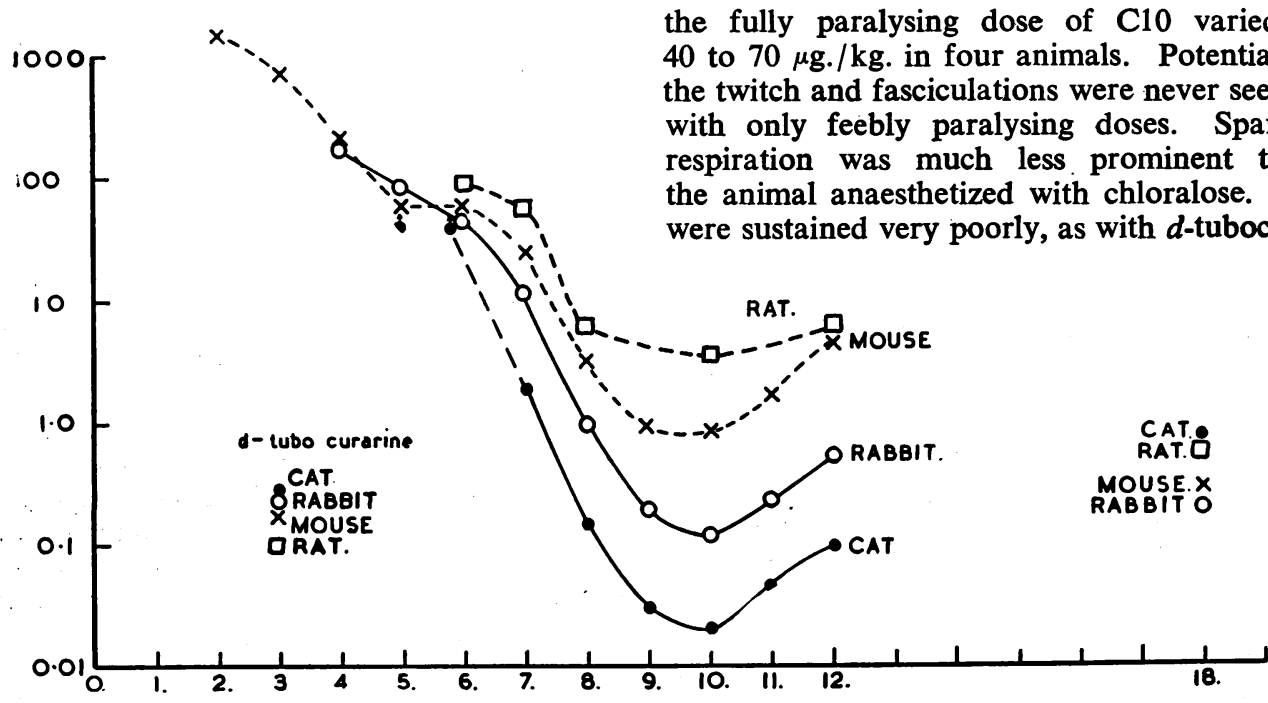

FIG. 7.-Variation of potency of bistrimethylammonium compounds, with varying length of polymethylene chain, and of $d$-tubocurarine chloride, among different species. Abscissa : number of carbon atoms in chain. Ordinate: dose in $\mathrm{mg} . / \mathrm{kg}$. (Extrapolation of the curves beyond $\mathrm{C12}$ to $\mathrm{C18}$ has not been attempted.)

volume has been observed ; a counterpart, perhaps, of the phase of potentiation of the muscle twitch which has been already mentioned. With larger doses of $\mathrm{C10}$, respiratory depression can of course be induced; but it is again remarkable how much sooner recovery of adequate respiration takes place than recovery of the normal muscle twitch.

In Fig. $6 b$ is also shown the record of a similar experiment with $d$-tubocurarine chloride. In contrast to $\mathrm{C10}$, distinct respiratory depression was produced, with an almost negligible effect on the tibialis twitch. Our experience has been consistently of this kind, that with $d$-tubocurarine chloride, respiratory depression accompanies or even precedes paralysis of the tibialis twitch.

The contrast between the two drugs in this respect appeared so striking that it will be reported more fully elsewhere.

\section{Effect of varying the anaesthetic}

Although most of our experiments were made with cats anaesthetized with chloralose, we have also used ether alone and pentothal alone. In the one experiment with pentothal anaesthesia, C10 appeared to be somewhat more effective than with chloralose, $20 \mu \mathrm{g}$. $/ \mathrm{kg}$. being adequate for complete abolition of the tibialis twitch, although respiration was only slightly depressed with the above dose. No preliminary potentiation or fasciculations were seen.

With ether (6-7 per cent), on the other hand, C10 was less effective than with chloralose, and the fully paralysing dose of $\mathrm{ClO}$ varied from 40 to $70 \mu \mathrm{g} . / \mathrm{kg}$. in four animals. Potentiation of the twitch and fasciculations were never seen, even with only feebly paralysing doses. Sparing of the animal anaesthetized with chloralose. Tetani were sustained very poorly, as with $d$-tubocurarine 


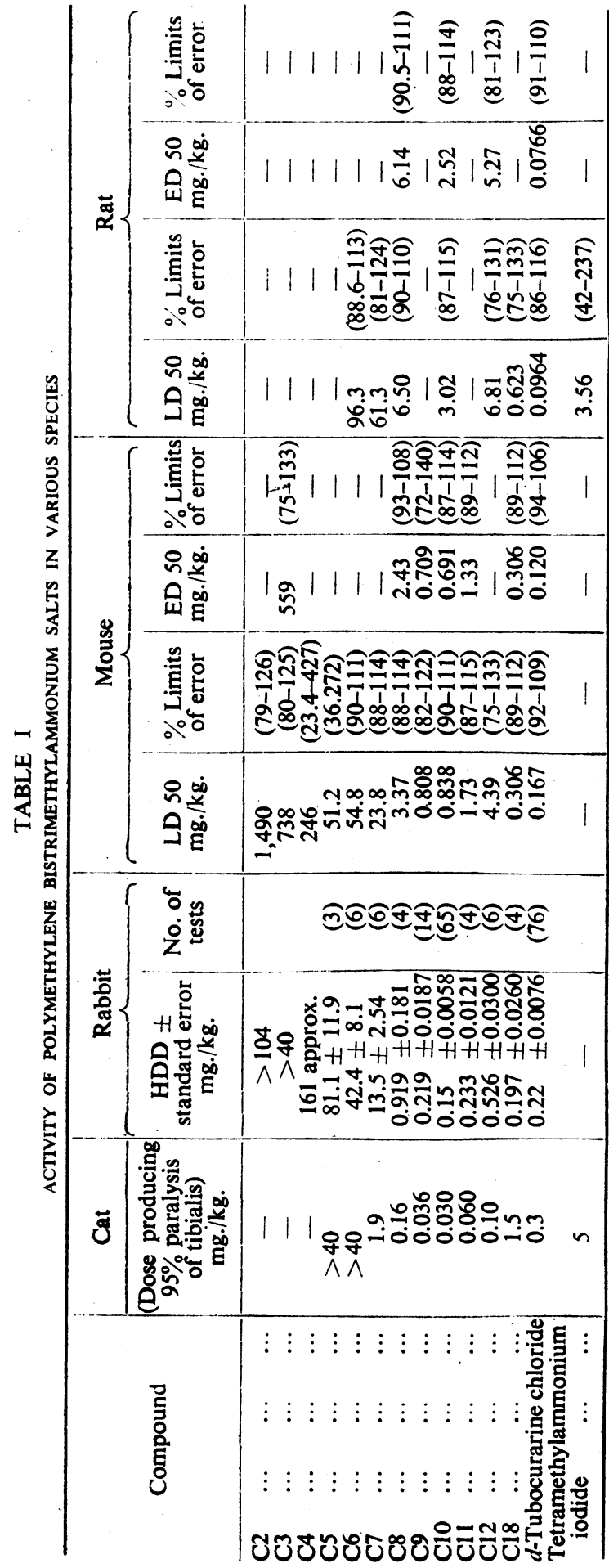

chloride. Indeed, the effects of ether could be said to resemble rather closely those of a previous dose of $d$-tubocurarine chloride, which are described below.

\section{Variation of potency with species}

Attempts to estimate the potency of these compounds led at once to the discovery of a very great variation with different species. For the bulk of the experiments different methods of testing were used with different species. Fig. 7 summarizes the results, which are shown in more detail in Table I, together with corresponding figures for $d$-tubocurarine chloride. Further experiments on a few of the compounds showed, however, that variation in the method of testing accounted for only a small part of the species difference. We took as a standard that dose (RD50) which, after injection rapidly by the intravenous route into unanaesthetized animals, causes loss of the ability to right themselves in half the animals. In cats this was very close to the dose required to reduce the twitch tension of tibialis by 95 per cent in the animal anaesthetized with chloralose; in rabbits, it was about 20 per cent less than the head-drop dose (HDD), and it was about 20 per cent less than the LD50 in mice and rats. The figures for monkey were direct estimates of RD50 ; those for man are based on some preliminary trials (Organe, Paton, and Zaimis, 1949) and represent the dose that made the subjects too weak to sit up or stand or lift any of their limbs. If the activity of $\mathrm{ClO}$ in the various species is corrected to this standard, comparable estimates of its potency in these species are obtained, and are shown in Table II. The results of tests on frogs are also included, but it must be remembered that the route of injection used (ventral lymph sac) was quite different from that in the other species.

The actions of these drugs on various species also differed in the manner of the paralysis, and several interesting points emerged. In the monkey, the earliest sign of weakness was an inability to keep the arm above the head ; after this appeared progressive weakness of movement and dropping of the head, and only with deep paralysis was the ability to sit up lost. In cats, the paralysis progressed more uniformly, and neck, trunk, and limbs seemed to weaken together; but an unusual and constant feature was the complete relaxation of the nictitating membrane for so long as the paralysis lasted: this relaxation is, indeed, the first sign of paralysis observed after an intravenous injection. Finally, in rabbits, weakness of the hindlegs appeared first, while further paralysis of the limbs and head-drop 
TABLE II

RELATIVE POTENCY OF C10 IN VARIOUS SPECIES, AS DOSE REQUIRED TO PARALYSE RIGHTING RĖACTION

\begin{tabular}{|c|c|c|c|c|c|c|c|c|}
\hline - Species: & Cat & Man & Baboon & Rabbit & Monkey & Mouse & Rat & - Frog \\
\hline $\begin{array}{l}\text { Dose mg./kg. C10 } \ldots \\
d \text {-Tubocurarine chloride }\end{array}$ & $\begin{array}{l}0.03 \\
0.3\end{array}$ & $\begin{array}{l}0.05 \\
0.25\end{array}$ & 0.14 & $\begin{array}{l}0.14 \\
0.20\end{array}$ & $\begin{array}{l}0.25 \\
0.09\end{array}$ & $\begin{array}{l}0.691 \\
0.120\end{array}$ & $\begin{array}{l}2.5 \\
0.0766\end{array}$ & $\begin{array}{c}10.9 \\
5.49\end{array}$ \\
\hline
\end{tabular}

followed. The opportunity was taken of administering $\mathrm{ClO}$ to one baboon (Papio anubis), weight $14.5 \mathrm{~kg}$., which was suffering from a traumatic paraplegia and was to be killed. After the slow injection of $\mathrm{C10}$ at a rate of $0.5 \mathrm{mg} . / \mathrm{min}$., headdrop occurred after $2 \mathrm{mg}$. had been injected, followed by almost complete skeletal paralysis; respiration was still adequate although depressed. Injection of $50 \mathrm{mg}$. of C5 $9 \mathrm{~min}$. later caused partial recovery of arm strength and deepening of respiration.

Variation of potency with length of polymelhylene chain

Despite the species variation, $\mathrm{C} 10$ was the most potent member of the series by any test for neuromuscular block. Its immediate neighbours in general closely resembled it qualitatively, although not in potency. The steepness of the curve relating potency to chain-length deserves comment ; for instance, shortening the polymethylene chain from eight to seven carbon atoms reduced potency more than tenfold. Members of the series remote from $\mathrm{Cl0}$, however, gave the impression that new activities were appearing. The abrupt change of slope in Fig. 7 in the region of C6 and the attenuation of the species difference with $\mathrm{C} 18$ are of great interest. Since head-drop and lethality are not specific tests for neuromuscular block, it is possible that the other pharmacological actions of the series described below become prominent in bringing about an end-point with the members of the series which are relatively inactive in causing neuromuscular block.

A point of interest lies in the activity of tetramethylammonium iodide relative to these compounds. A dose of $5 \mathrm{mg} . / \mathrm{kg}$. injected intravenously into a cat produced an effect on tibialis twitch comparable with that of $30-40 \mu \mathrm{g}$. $/ \mathrm{kg}$. of C10. This potency, although small, is greater than that of $\mathrm{C} 4, \mathrm{C5}$, and $\mathrm{C6}$, which fail to depress neuromuscular transmission in doses of $\mathbf{4 0} \mathrm{mg} . / \mathrm{kg}$. Our results with mice, rats, and rabbits indicate that $\mathrm{C2}$ and $\mathrm{C} 3$ are equally or even more inactive in this respect.

\section{Interaction of C10 with d-tubocurarine chloride}

Our first attempts to compare the potencies of these two drugs on the cat's tibialis yie'ded puzzling results, until it was realized that $\mathrm{C} 10$ was less effective than usual when $d$-tubocurarine chloride had been given previously. Fig. $1 a$ and $1 b$ illustrates this point on cat's tibialis. It can also be shown on the rabbit head-drop, and a typical experiment is cited in Table III. In this experiment the preliminary dose of curare was such as caused distinct (although transient) weakness of

TABLE III

EFFECT OF PREVIOUS ADMINISTRATION OF $d$-TUBOCURARINE CHLORIDE ( $d$-TC) ON SENSITIVITY TO C10

Cross-over test on four rabbits; $0.15 \mathrm{mg}$. $d$-tubocurarine chloride per $\mathrm{kg}$. i.v. $15 \mathrm{~min}$. before test

\begin{tabular}{|c|c|}
\hline \multicolumn{2}{|c|}{ Rabbit HDD (mg./kg.) } \\
\hline C10 alone & C10 after $d-\mathrm{TC}$ \\
\hline $\left.\begin{array}{l}0.088 \\
0.222 \\
0.104 \\
0.109\end{array}\right\}$ day 1 & $\left.\begin{array}{l}0.224 \\
0.365 \\
0.171 \\
0.176\end{array}\right\}$ day 2 \\
\hline
\end{tabular}

Dose of $\mathrm{C10}$ after $d$-TC

Dose of $\overline{C 10}$ alone $=1.81$ (limits of error for $P=$ 0.05: 1.10-2.99)

TABLE IV

EFFECT OF PREVIOUS ADMINISTRATION OF C10 ON SENSITIVITY TO $d$-TUBOCURARINE CHLORIDE

Cross-over test on four rabbits; $0.075 \mathrm{mg}$. C10 per $\mathbf{~ k g}$. i.v. $15 \mathrm{~min}$. before test

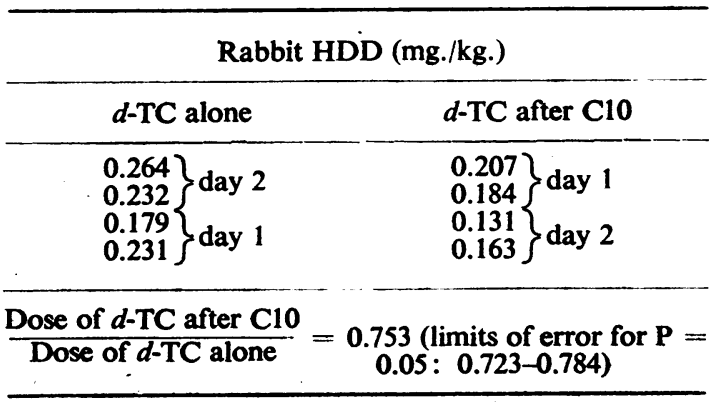




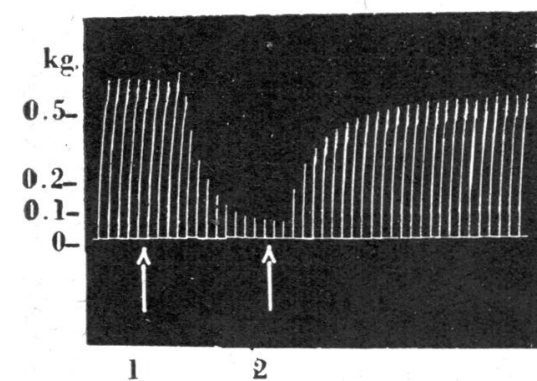

(a)

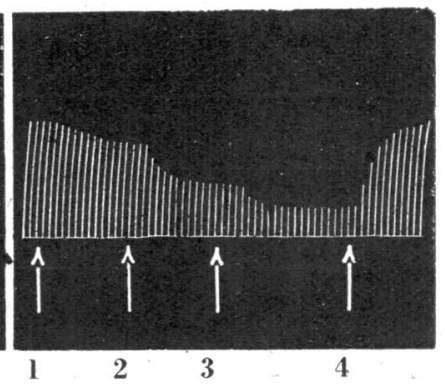

(b)

FIG. 8.-(a) Cat, chloralose, $2.2 \mathrm{~kg}$. Tibialis: nerve shocks every $10 \mathrm{sec} \cdot$ At (1), $0.1 \mathrm{mg}$. C10i.v. At (2), $10 \mathrm{mg}$. C5 i.v. (b) Cat, chloralose, $2.8 \mathrm{~kg}$. Tibialis: nerve shocks every $10 \mathrm{sec}$. At (1), (2), (3), $1 \mathrm{mg}$., $0.5 \mathrm{mg}$., $0.5 \mathrm{mg}$., respectively, $d$-tubocurarine chloride i.v. At (4), $0.5 \mathrm{mg}$. neostigmine i.v.

the animals ; nevertheless, a larger dose of $\mathrm{C10}$ was required subsequently to produce head-drop. The previous administration of $\mathrm{C10}$ does not (despite its feeble anticholinesterase action) lessen the effect of $d$-tubocurarine chloride, but rather augments it to a slight degree according to the interval between the injections (Table IV).

This antagonistic effect of $d$-tubocurarine chloride is detectable in the rabbit for an hour and in the cat may persist for a similar period. The duration of the antagonism and its effectiveness become greater as the dose is increased. In addition, the fasciculations and potentiation normally produced by $\mathrm{C} 10$ are uniformly abolished.

These actions are not specific to $d$-tubocurarine chloride; we have observed them also with its methyl ether, $d$-bebeerine methiodide, $\mathrm{N}$-methyldiaboline iodide, and with tri(diethylaminoethoxy)benzene triethiodide ("Flaxedil").

\section{TABLE V}

EFFECT OF PREVIOUS ADMINISTRATION OF NEOSTIGMINE METHYL SULPHATE ON SENSITIVITY TO C10

Cross-over test on four rabbits; $0.05 \mathrm{mg}$. neostigmine methyl sulphate per $\mathrm{kg}$. i.v. $1 \mathrm{~min}$. before test

\begin{tabular}{|c|c|}
\hline \multicolumn{2}{|c|}{ Rabbit HDD (mg./kg.) } \\
\hline C10 alone & $\mathrm{Cl0}$ after neostigmine \\
\hline $\left.\begin{array}{l}0.117 \\
0.156 \\
0.203 \\
0.121\end{array}\right\}$ day 1 & $\left.\begin{array}{l}0.112 \\
0.154 \\
0.232 \\
0.112\end{array}\right\}$ day 2 \\
\hline
\end{tabular}

Dose of C10 after neostigmine Dose of C10 alone drop test, a dose of $0.05 \mathrm{mg}$. neostigmine methyl sulphate per $\mathrm{kg}$., previously given, which increased the HDD of $d$-tubocurarine chloride from $0.316 \mathrm{mg}$. $/ \mathrm{kg}$. to $0.615 \mathrm{mg}$. $/ \mathrm{kg}$. in four rabbits, did not alter the HDD dose of C10 significantly from $0.149 \mathrm{mg}$. $/ \mathrm{kg}$. (Table V).

Observations on the frog's rectus, in which $\mathrm{ClO}$ produces a contracture, showed that lower members of the series, inactive both in causing neuromuscular block and in producing a contracture, antagonized this action of $\mathrm{C10}$ : C5 and C6 were

\section{TABLE VI}

EFFECT OF PREVIOUS ADMINISTRATION OF C6 ON SENSITIVITY TO C10 AND TO $d$-TUBOCURARINE CHLORIDE

Cross-over tests on four rabbits; $10 \mathrm{mg}$. C6 per kg. i.v. $5 \mathrm{~min}$. before test

\begin{tabular}{|c|c|}
\hline \multicolumn{2}{|c|}{ Rabbit HDD (mg./kg.) } \\
\hline C10 alone & $\mathbf{C 1 0}$ after $\mathbf{C 6}$ \\
\hline $\left.\begin{array}{l}0.100 \\
0.116 \\
0.153 \\
0.147\end{array}\right\}$ day 1 & $\left.\begin{array}{l}0.180 \\
0.273 \\
0.240 \\
0.195\end{array}\right\}$ day 2 \\
\hline
\end{tabular}

$\underline{\text { Dose of } \mathrm{C10} \text { after } \mathrm{C6}}=1.69$ (limits of error for $\mathrm{P}=$ $\overline{\text { Dose of C10 alone }}=0.05: 1.23-2.41$ )

\begin{tabular}{|c|c|}
\hline$d$-TC alone & $d$-TC after C6 \\
\hline $\left.\begin{array}{l}0.177 \\
0.336 \\
0.266 \\
0.280\end{array}\right\}$ day 2 & $\left.\begin{array}{l}0.163 \\
0.392 \\
0.181 \\
0.227\end{array}\right\}$ day 1 \\
\hline
\end{tabular}

Dose of $d$-TC after $\mathrm{C} 6$ Dose of $d$-TC alone $=0.878$ (limits of error for $P=$ 0.05: $0.638-1.21$ ) 
particularly effective in this respect. This suggested that such antagonism might also exist at the : mammalian neuromuscular junction. Fig. 8, a record of an experiment to test the point on the cat's tibialis with $\mathrm{C} 5$, shows that this expectation was fulfilled. Table VI summarizes the results of a similar experiment with $\mathrm{C} 6$ using the rabbit head-drop method. Table VI also shows that C6 not only has no antagonistic action to $d$-tubocurarine chloride but may even potentiate its action somewhat.

The antagonistic action of C5 (and C6) is complicated to some extent by their ganglionic action (described below), and with large doses there is no doubt that a fall of blood pressure occurs which is due to paralysis of sympathetic vascular tone. This does not, however, affect the recovery of neuromuscular transmission when C5 is administered during a paralysis due to C10. A useful antidotal action can be observed in rabbit and monkey where the dose of $\mathrm{C5}$ is only ten times that of the paralysing dose of $\mathrm{C10}$, and under these conditions vascular effects are trivial. With this ratio of doses, shallow paralyses are cut short, recovery from deeper paralyses is accelerated, and respiratory depression due to larger doses still is greatly lessened. On the cat tibialis preparation, however, a larger ratio of $\mathrm{C5}$ to $\mathrm{C10}$ is usually required, and $3 \mathrm{mg}$. $/ \mathrm{kg}$. C5 may be required for a prompt antagonism. The antagonistic action of $\mathrm{C5}$ is easily reversed by increasing the dose of $\mathrm{C10}$, and the renewed onset of neuromuscular block can be again antagonized by further doses of $\mathrm{C5}$; there is a limit to this process, however, and with very large doses of $\mathrm{C} 5$ little more recovery from neuromuscular block can be obtained. Similarly, after large doses of $\mathrm{C10}$ it is difficult to demonstrate any antagonism (just as neostigmine is not very effective after large doses of curare).

Potassium has been shown to antagonize the neuromuscular block due to curare (Wilson and Wright, 1936). We have therefore tested it against a similar block due to $\mathrm{C10}$ (Fig. $9 b$ ). It will be seen that there is no important action, although the dose is enough (when given to the unparalysed muscle) to produce a typical potentiation of the twitch (Fig. 9a). Adrenaline appears to be equally ineffective.

\section{Paralysis of autonomic ganglia}

A few seconds after the injection of $10 \mathrm{mg}$. of C6 into a rabbit, we observed that its ears flushed vigorously and became warm, and we have already mentioned the ability of $\mathrm{C5}$ and $\mathrm{C} 6$ to cause a fall of blood pressure. The analysis of these effects revealed that these compounds paralyse autonomic ganglia. The evidence for this will be presented in another paper. For the present we wish only to describe the experiments made to compare quantitatively the potencies of
FIG. 9.-Cat, chloralose, 2.8 kg. Tibialis : nerve shocks every $10 \mathrm{sec}$. In t r a-arterial injections: (a) At $\mathrm{K}, 3 \mathrm{mg}$. KCl. (b) At C10,4 $\mu$ g. C10; at $\mathrm{A}, 5 \mu \mathrm{g}$. acetylcholine ; at $\mathrm{K}, 3 \mathrm{mg}$. $\mathrm{KCl}$.

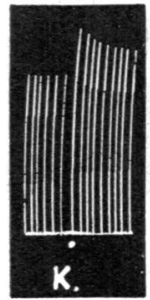

(a)

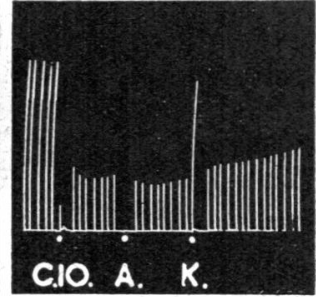

(b)
C6 and its neighbours in this respect. The cat's nictitating membrane, excited to a sustained contraction by stimulation of the preganglionic cervical sympathetic trunk at a frequency of 10 shocks per second, provided a useful test for activity of these compounds on transmission in the superior cervical ganglion. Fig. 10 shows a typical tracing in which $\mathrm{C} 5$ and $\mathrm{C} 6$ and tetraethyl-

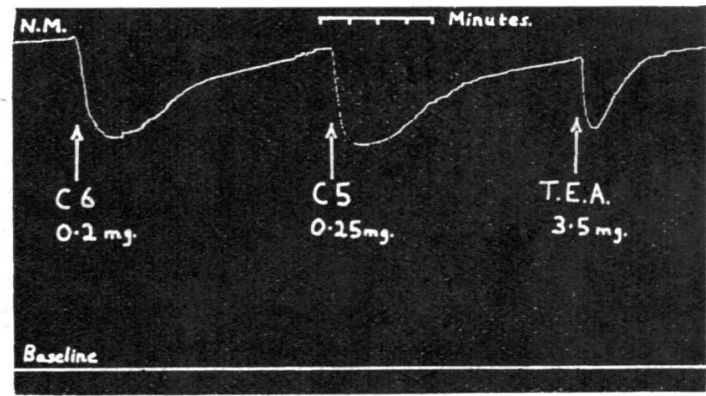

Fig. 10.-Cat, chloralose. Record of sustained contraction of nictitating membrane excited by stimulation of cervical sympathetic $10 \mathrm{sec}$. intravenous injections. Effects of $0.2 \mathrm{mg}$. C6; $0.25 \mathrm{mg}$. C5; and $3.5 \mathrm{mg}$. tetraethylammonium iodide (T.E.A.).

ammonium iodide were compared. Table VII gives a summary of those doses of these compounds and of tetraethylammonium iodide which caused roughly equal peak relaxations of the nictitating membrane. There was a considerable difference between C5 and C6 and tetraethylammonium iodide in their duration of action, the former two drugs acting more slowly and exerting their action three to four times as long as the latter, for doses which gave equal peak effects. 

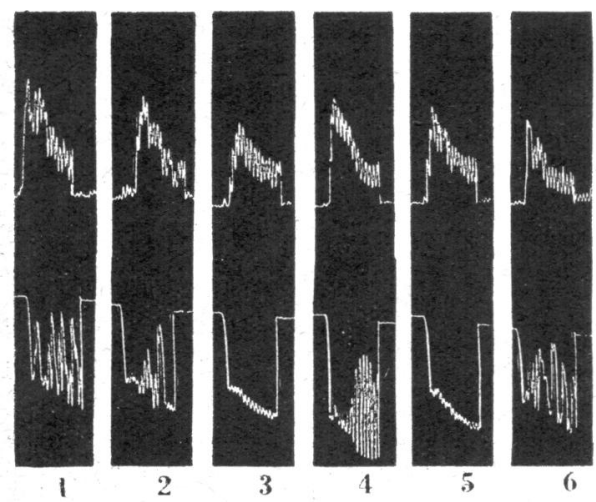

(a)

Fig. 11.-Isolated rabbit intestine. Record of length (upper tracing) and volume (lower tracing) ; intestine stimulated by rapid rise of intra-intestinal pressure of $3 \mathrm{~cm}$. water. (a) 1, normal response. $2,0.1 \mathrm{mg}$. C6 added to bath. 3, 0.2 mg. C6. $4,15 \mu \mathrm{g}$., and $5,30 \mu \mathrm{g}$. $d$-tubocurarine chloride. 6 , normal response. (b) 1, Normal response. $2,0.3 \mathrm{mg}$. C6. $3,2.0 \mathrm{mg}$. tetraethylammonium iodide. 4, Normal response.

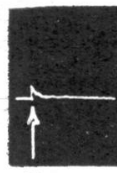

C6

$2 \times 10^{-3}$

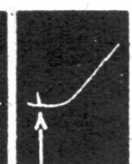

C7
CII

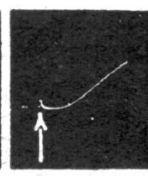

$1.2 \times 10^{-6}$

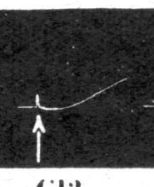

C.12

$10-6$

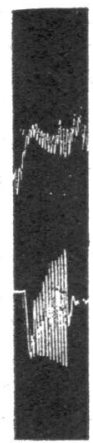

1

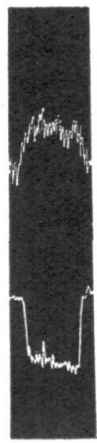$$
\text { (b) }
$$

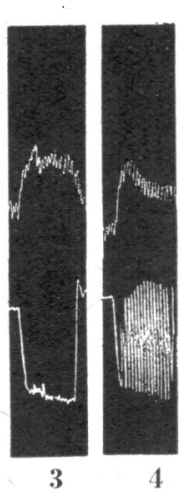

4
FIG. 12.-Frog's rectus. Contractions elicited by (1) $2 \times 10^{-3} \mathrm{C6}$; (2) $10^{-4} \mathrm{C7}$; (3) $1.2 \times 10^{-6} \mathrm{Cl1}$; (4) $10^{-6} \mathrm{C} 12$; (5) $1.1 \times 10^{-6} \mathrm{Cl1}$; (6) $1.4 \times 10^{-6} \mathrm{Cl0}$; (7) $10^{-6} \mathrm{C} 12$; (8) $10^{-4} \mathrm{C} 18$.

To test the effect on parasympathetic autonomic ganglia, we used the technique of Trendelenburg described by Feldberg and Lin (1949). Fig. 11 shows typical tracings, and Table VII gives the relative potencies of the compounds tested. It was again observed by comparing the ease with which they could be washed out that C5 and C6

\section{TABLE VII}

Relative potencies in causing relaxation of cat's nictitating membrane, excited by stimulation of cervical sympathetic trunk. (Arbitary scale, $\mathrm{C6}=100$.)

Compound: C4 C5 C6 C7 C8 Tetraethylam-

Potency: $\quad 2 \quad 80 \quad 100 \quad 10 \quad 2 \quad \begin{gathered}\text { monium iodide } \\ 5\end{gathered}$

Relative potencies on peristaltic reflex of small intestine (Arbitary scale, $\mathrm{C6}=100$.)

Compound: C2 C3 C4 C5 C6 C7 $\begin{gathered}\text { ammonium } \\ \text { iodide }\end{gathered}$

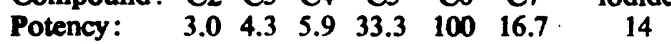

peristaltic waves (particu-

larly C12); but this action was slight, and could be ascribed to their anticholinesterase activity.

\section{Stimulation of skeletal muscle}

It was at first supposed that it would be possible to show on the frog's rectus an antagonism by $\mathrm{ClO}$ of the effects of acetylcholine similar to that exerted by $d$-tubocurarine chloride. It was found, however, that $\mathrm{C} 10$ itself stimulates the frog's rectus to contraction. Whether applied in low or high concentrations, and whether allowed to act briefly or for 10-15 min., no signs of any other than stimulant activity appeared. Indeed, so far from antagonizing acetylcholine, it usually potentiated its effects slightly, probably because of C10's weak anticholinesterase activity.

The contraction produced by $\mathrm{C10}$ and its neighbours (Fig. 12) differs in several respects from that caused by acetylcholine (Fig. 14); it has a slower onset, and does not so readily reach a plateau; after $\mathrm{C} 10$ has been washed out, a longer time is 

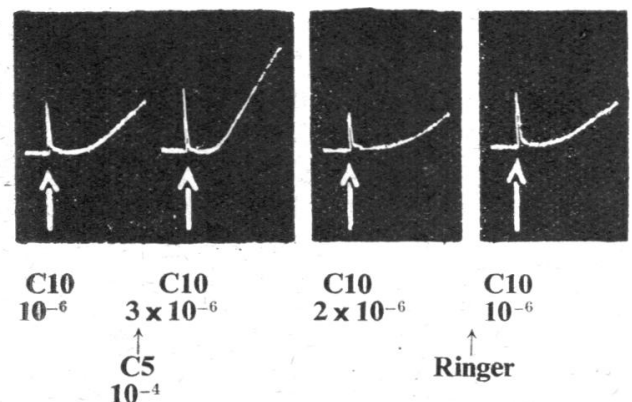

FIG. 13.-Frog's rectus. Antagonism of contracture due to $\mathrm{C} 10$ by $\mathrm{C} 5$. (1) $10^{-6} \mathrm{C10}$; (2) $3 \times 10^{-6} \mathrm{Cl0}$; (3) $2 \times 10^{-6} \mathrm{ClO}$; (4) $10^{-6} \mathrm{C10}$. During (2) and (3) Ringer contained $10^{-4} \mathrm{C} 5$.
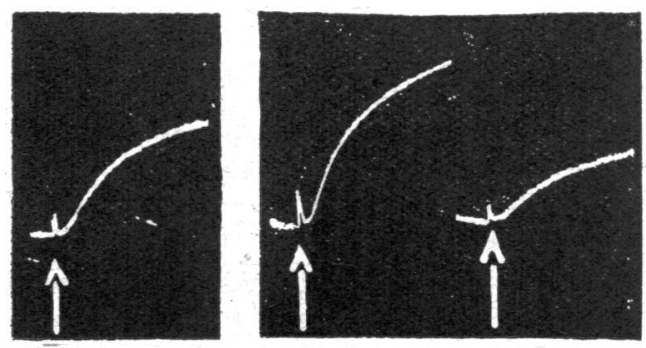

$\mathrm{ACh}$

$10^{-7}$
FKG. 14.-Frog's rectus. Antagonism of contracture due to acetylcholine by C6. (1) $10^{-7} \mathrm{ACh}$; (2) $3.3 \times 10^{-7}$ ACh; (3) $2 \times 10^{-7} \mathrm{ACh}$ : During 2 and 3, Ringer contained $10^{-4} \mathrm{C} 6$.

needed to obtain proper muscular relaxation. Its dose-response curve is, however, not dissimilar to that of acetylcholine and it resembles acetylcholine in one important respect, that its action is also antagonized by $d$-tubocurarine chloride and by fairly high concentrations of atropine $\left(10^{-4}\right)$.

Measurements were made of the relative potency of the members of the series with respect to each other and to acetylcholine (Table VIII). During this part of the experiment, the fact mentioned above emerged, that the shorter chain compounds,

TABLE VIII

Relative potencies in stimulating frog's rectus abdominis. (Arbitary scale, $\mathrm{C} 12=100$.)

Acetyl-

Compound: C6 C7 C8 C9 C10 C11 C12 C18 choline $\begin{array}{lllllllllll}\text { Potency: } & 0.1 & 1.3 & 7.1 & 36 & 71 & 91 & 100 & 1.3 & 1,500\end{array}$ which are inactive in causing contractures, were nevertheless exerting an action on the muscle, since they diminished the contractions elicited by the longer chain compounds (Fig. 13). The antagonism to $\mathrm{C10}$ was a maximum with $\mathrm{C} 5$, closely rivalled by $\mathrm{C} 6$. Table IX gives the concentrations

TABLE IX

Inhibitory concentrations against $\mathrm{ClO}$, tested on frog's rectus. (Concentration causing 50 per cent inhibition.)

$\begin{array}{lccc}\text { Compound: } & \mathrm{C} 4 & \mathrm{C} 5 & \mathrm{C} 6 \\ \text { Concentration: } & 8 \times 10^{-5} & 5.0 \times 10^{-5} & 5.5 \times 10^{-5}\end{array}$

of the members tested which caused 50 per cent inhibition of $\mathrm{C} 10$. It was also observed that $\mathbf{C 5}$ and $\mathrm{C} 6$ can antagonize the contracture produced by acetylcholine (Fig. 14).

The stimulation of skeletal muscle could also be demonstrated in the cat (Figs. 4 and 9). In these experiments a few $\mu \mathrm{g}$. of $\mathrm{C} 10$ were injected rapidly into the artery of a tibialis prepared for close arterial injection, during an intermission of stimulation ; just as after a similar injection of acetylcholine there was a fast contraction of the muscle which followed the injection so rapidly as to seem synchronous with it. After the rapid contraction is complete, there is often left a small residual contraction for a few seconds, which is followed by the onset of neuromuscular block. Roughly, the dose of $\mathrm{ClO}$ required to produce a twitch of the muscle is one which produces a substantial neuromuscular block; smaller doses are ineffective in both respects, and larger doses produce a larger twitch before long-lasting block ensues. It does not appear to be possible with any dose by this route to obtain paralysis without evidence of stimulation first, except by making the injection rather slowly.

After intravenous injections of $\mathrm{C10}$ we have never seen the rapid twitch just described; but large doses may elicit a small contraction lasting 10-20 sec., of a few grammes tension. No detailed comparison with other members of the series has been made ; but, in general, our experiments are not inconsistent with the ranking of potency in stimulating muscle, which we obtained on frog's rectus.

\section{Anticholinesterase potency}

Anticholinesterase activity was tested by two methods in order to distinguish between the activities of the compounds against the so-called "true" and "pseudo" cholinesterases. For the former, acetyl- $\beta$-methylcholine and laked rabbit cells 
TABLE $X$

ACTIVITY IN INHIBITING CHOLINESTERASE

Substrate concentrations: for " true" enzyme $0.027 M$ acetyl- $\beta$-methylcholine; for " pseudo" enzyme $0.0055 M$ benzoylcholine

\begin{tabular}{|c|c|c|c|}
\hline \multicolumn{2}{|c|}{ Compound } & $\begin{array}{c}\text { "True" } \\
\text { concentration for } \\
50 \% \text { inhibition }\end{array}$ & $\begin{array}{l}\text { "Pseudo" } \\
\% \text { inhibition at a } \\
\text { concentration of } \\
1.25 \times 10^{-8}\end{array}$ \\
\hline $\begin{array}{l}\mathrm{C} 7 \ldots \\
\mathrm{C} 8 \ldots \\
\mathrm{C} 9 \ldots \\
\mathrm{C} 10 \\
\mathrm{C} 11 \\
\mathrm{C} 12 \\
\mathrm{C} 18\end{array}$ & \begin{tabular}{l|}
$\ldots$ \\
$\ldots$ \\
$\ldots$ \\
$\ldots$ \\
$\ldots$ \\
$\ldots$
\end{tabular} & $\begin{array}{l}3.5 \times 10^{-3} \\
1.0 \times 10^{-3} \\
1.2 \times 10^{-4} \\
4.5 \times 10^{-5} \\
1.8 \times 10^{-5} \\
5.6 \times 10^{-6} \\
1.4 \times 10^{-5}\end{array}$ & $\begin{array}{r}8 \\
35 \\
97\end{array}$ \\
\hline $\begin{array}{l}\text { Eserine } \\
d \text {-TC }\end{array}$ & $\begin{array}{l}\cdots \\
\cdots \\
.\end{array}$ & $\begin{array}{l}7.1 \times 10^{-8} \\
1.1 \times 10^{-3}\end{array}$ & 10 \\
\hline
\end{tabular}

were used; for the latter, benzoylcholine and rabbit plasma as source of esterase. The compounds had little activity against " pseudo" cholinesterase, and it was not thought worth while to study their actions at concentrations higher than $1.25 \times 10^{-3}$. The values obtained are shown in Table X. Against true cholinesterase, however, the longer chain members had appreciable activity, and sufficient determinations were made to be able to estimate the concentration of drug causing 50 per cent inhibition of the enzyme ; this figure for each member of the series is given in Table $X$, and has been plotted in Fig. 15. Comparable figures for eserine are included in Table $\mathbf{X}$; it is about 650 times more active than $\mathrm{C} 10$ against true cholinesterase.

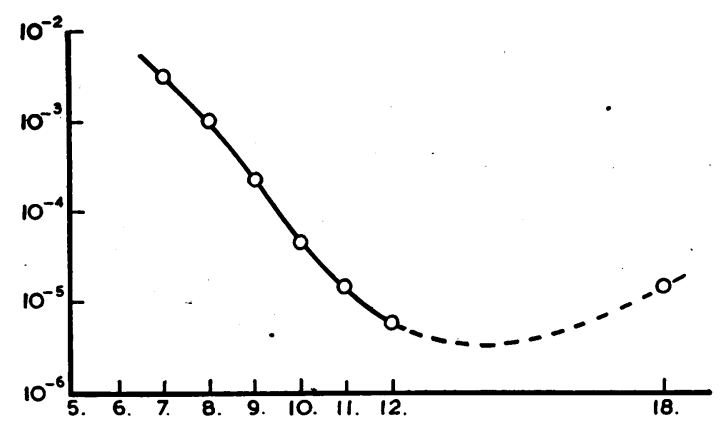

FIG. 15.-Variation of activity of bistrimethylammonium compounds against " true" cholinesterase, with varying length of polymethylene chain. Abscissa: number of carbon atoms in polymethylene chain. Ordinate: concentration for 50 per cent inhibition of the " true" cholinesterase. .Substrate: $0.027 M$ acetyl- $\beta$-methylcholine.
A point of some interest is the selective paralysis of "true" cholinesterase; this, no doubt, is a function of the particular enzymes chosen. But the degree of selectivity is considerable ; by extrapolation, it can be estimated that $\mathrm{C10}$ is 200 times more active against "true" than against "pseudo" cholinesterases, and $\mathrm{C} 12$ about 600 times.

We have referred already to the potentiation of the twitch during the early stages of a block by C10. Records of the muscle action potential (Fig. 3B) show repetitive firing of the fibre in response to single shocks, similar to that wellestablished for eserine and diisopropyl fluorophosphonate. The possibility can be raised therefore that $\mathrm{C10}$, although far less active than eserine in vitro as an anticholinesterase, becomes relatively more effective because of its lack of affinity for pseudocholinesterase in plasma. It is also possible, however, that the stimulant action of $\mathrm{C10}$ on the muscle must be taken into account in explaining the fasciculations, potentiation of the twitch, and repetitive firing (cf. Zaimis, 1949).

\section{Muscarine-like action and atropine-like action}

Tetramethylammonium ion has a muscarine-like action, and it was of interest to determine whether these closely related compounds also shared it. But such activity as they possess is very slight, and could only be demonstrated easily on the isolated guinea-pig or rabbit intestine; the most active compound tested $(\mathrm{C12})$ was about 1,300 times less active than acetylcholine. Atropine in a concentration of $4 \times 10^{-9}$ in the bath abolished contractions due to both these drugs. No corresponding depressor action could be demonstrated when these compounds were tested on the cat's blood pressure

\section{TABLE XI}

Relative potencies in stimulating small intestine. (Arbitrary scale, $\mathrm{C12}=100$.)

Compound: C2 C4 C5 C6 C7 C8 C9 C10 C11 C12 C18 $\begin{aligned} & \text { Acetyl- } \\ & \text { choline }\end{aligned}$

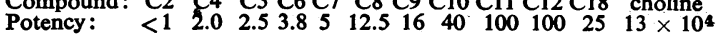

in intravenous doses up to $10 \mathrm{mg}$. $/ \mathrm{kg}$. Table XI gives the estimated relative potencies of the series. A depressor action characteristic of certain histamine-liberators is discussed below.

Search was also made for an atropine-like action, with the response of the cat's blood pressure to acetylcholine as a test object. A dose of $10 \mathrm{mg}$. C10 did not diminish the action of acetylcholine, but rather enhanced it slightly. It appeared possible that the anticholinesterase action of C10 might be masking a feeble atropine-like action. The experiment was therefore repeated in 
an eserinized animal, so that inactivation of cholinesterase should be complete before $\mathrm{C} 10$ was given ; but it was again impossible to demonstrate any depression of the response to acetylcholine by the injection of $\mathrm{C10}$. We obtained a similar result on the isolated guinea-pig's ileum. The contraction of the gut elicited by acetylcholine $\left(2 \times 10^{-9}\right.$; final concentration in the bath) was neither prevented nor diminished by the previous or later addition of $\mathrm{C} 10$ to a final concentration of $2 \times 10^{-6}$, a concentration sufficient to cause a contraction of the gut due to the $\mathrm{C} 10$ itself.

\section{Release of histamine}

Mention was made at the beginning of this paper that this series is not active in eliciting the delayed depressor response of the cat's blood pressure, characteristic of histamine liberation. This response can, however, be obtained, and Fig. 16

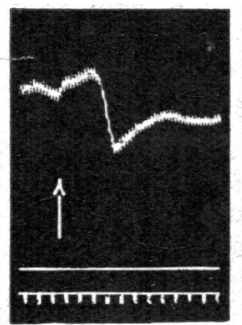

(1)

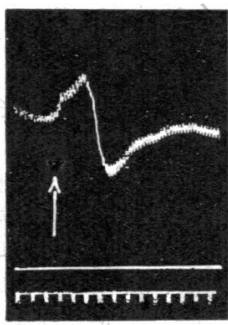

(2)

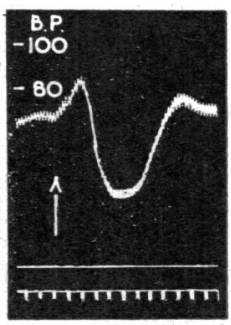

(3)
Frg. 16.-Cat, chloralose. Atropine (4 mg.), nicotine (7 mg.) previously. (1) $20 \mathrm{mg} . \mathrm{C} 12 \mathrm{i.v.}$ (2) $1 \mathrm{mg}$. propamidine isethionate i.v. (3) $5 \mathrm{mg}$. $d$-tubocurarine chloride i.v. $(12 \mathrm{~min}$. between successive tests.)

gives a typical illustration of the action of $\mathrm{C12}$, with corresponding effects by $d$-tubocurarine chloride and propamidine for comparison (cf. MacIntosh and Paton, 1949). We have not studied this activity closely since it is so feeble compared with that in paralysing neuromuscular transmission. It appears, however, that $\mathrm{C} 12$ is a little more active than $\mathrm{C10}$ in this respect.

\section{Chronic toxicity}

C10.- This drug was injected intravenously in a dose of $30 \mu \mathrm{g} . / \mathrm{kg}$. into each of three cats, and in a dose of $100 \mu \mathrm{g} . / \mathrm{kg}$. into each of three rabbits, six times a week for a period of five to six and a half weeks. During this time there was no consistent change in sensitivity to the drug, although day-to-day variations occurred; sometimes only weakness resulted, at other times a profound paralysis. The veins through which the injections were made (of the leg in cat, of the ear in rabbit) did not become thrombosed, and the animals maintained their normal weight and health. One rabbit and one cat, having become deeply curarized after a daily injection of $\mathrm{C10}$, died before their course of six weeks was quite complete, despite artificial respiration. It must be remembered, however, that it is not easy to curarize animals repeatedly without getting occasional casualties, unless elaborate preparations for artificial respiration are made. One cat was killed as soon as it began to sicken at a time that an epidemic of agranulocytic panleucopenia was rife. Post-mortem findings showed in this animal only those changes typical of the disease. In the other animals there were no evidences of abnormality.

C6. - C6 was injected into the marginal ear vein of each of three rabbits, in a dose of $10 \mathrm{mg} . / \mathrm{kg}$., six days a week for a month. This dose is more than a hundred times the dose which is effective in man. Flushing of the ears was consistently observed, but there was no change in health or weight of the animals, and it was possible in two of the animals to make all the injections into one vein only. Post-mortem findings are given below.

If these compounds possessed any chronic toxicity it would probably be of the kind described for another aliphatic dibasic compound "synthalin" (diguanidinodecane) in which parenchymatous changes, particularly of liver and kidney, are prominent. There was no evidence either of these changes or of any other harmful action which could be ascribed to the chronic administration of these drugs.

\section{Post-mortem findings}

Sections were taken from lungs, heart, liver, gall bladder, spleen, small and large intestine, kidney, adrenals, testes, lymph glands, bone marrow, brain, and dura mater.

In the rabbits, slight peribronchiolar and perivascular lymphocytic infiltration of the lungs was observed, with occasional small areas of ulceration. These changes were also seen in control animals, and were regarded as normal.

C10. Cat 1. Chronic abscess of one mesenteric gland, but no intestinal lesion. No other abnormality.

Cat 2. (Died after daily dose.) Pulmonary oedema. No other abnormality.

Cat 3. (Sickened during epidemic of panleucopenia.) Changes in gut, lymph glands, and marrow, typical of disease. No other abnormality.

Rabbit 1. Normal.

Rabbit 2. (Died after daily dose.) Pulmonary oedema and haemorrhages. No other abnormality. 
Rabbit 3. Not killed. Alive and well 1 year later. C6. Rabbit 1. Normal.

Rabbit 2. Scanty focal patches of infiltration of meninges by lymphocytic cells. No other abnormality.

Rabbit 3. (Killed 4 months after last injection of C6.) The pia arachnoid contains an obvious excess of round cells of lymphocytic type, and similar cells accompany many of the penetrating vessels (cf. Rabbit 2). Fairly common areas of perivascular infiltration occur deeply and irregularly within the brain substance. Several foci of neuroglial proliferation are found in the cerebral hemispheres, unrelated to blood vessels, to recent destructive lesions, or to anatomical structures. Their significance is quite obscure. No other abnormality.

\section{Antibacterial action}

Although there was no reason to suppose that this series of compounds possessed an important antibacterial action, it seemed of interest to determine how far this activity varies with the length of the polymethylene chain. We are much indebted to Dr. A. T. Fuller for testing them for us. Table XII gives the concentrations of the various

\section{TABLE XII}

Inhibitory concentration of polymethylene bistrimethylammonium salts in $\mathrm{mg} . / 100 \mathrm{ml}$. (parts per 100,000).

\begin{tabular}{ll|c|c|c}
\hline \multicolumn{2}{c|}{ Compound } & Streptococci & Staphylococci & B. coli \\
\hline C2 & $\ldots$ & 500 & $>500$ & $>500$ \\
C3 & $\ldots$ & 500 & $>1,000$ & $>1,000$ \\
C4 & $\ldots$ & 1,000 & $>1,000$ & $>1,000$ \\
C5 & $\ldots$ & 500 & $>1,000$ & $>1,000$ \\
C6 & $\ldots$ & 500 & $>1,000$ & $>1,000$ \\
C7 & $\ldots$ & 500 & $>1,000$ & $>1,000$ \\
C8 & $\ldots$ & 750 & $>1,000$ & $>1,000$ \\
C9 & $\ldots$ & 500 & 1,000 & $>1,000$ \\
C10 & $\ldots$ & 300,300 & 1,000 & $>1,000$ \\
C11 & $\ldots$ & 200 & 200 & $>500$ \\
C12 & $\ldots$ & 150,100 & 100,200 & 100,200 \\
C13 & $\ldots$ & 50 & 50 & 50 \\
C18 & $\ldots$ & 0.3 & 0.8 & 8 \\
. & & & & \\
\hline
\end{tabular}

compounds which prevent visible growth in 18 hours at $37^{\circ} \mathrm{C}$. of streptococci, staphylococci, and $B$. coli. The antibacterial activity is negligible from $\mathrm{C} 3$ to $\mathrm{C12}$, and is only appreciable with C18. Even with the latter compound, however, the activity is only of theoretical interest.

\section{The surface tension of aqueous. solutions of the bistrimethylammonium series}

The change of pharmacological action with polymethylene chain length among these compounds clearly raised the question as to how far this might be due to change in the proportion of hydrocarbon chain to polar groups in the molecule. The measurement of surface tension at an air-water interface provided a suitable method for studying this. Table XIII gives the values obtained

\section{TABLE XIII}

Depression of surface tension of water by polymethylene bistrimethylammonium salts (concentration $1 \mathrm{mg}$./c.c.). Compound: C2 C3 C4 C5 C6 C7 C8 C9 C10 C11 C12 C13 C18 $\Delta \gamma\left(\frac{\text { dynes }}{\mathrm{cm} .}\right): \begin{array}{lllllllllllll}0.4 & 0.4 & 0.1 & 1.3 & 1.0 & 1.4 & 0.6 & 1.8 & 1.3 & 1.3 & 4.0 & 4.3 & 19.3\end{array}$

for the depression of the surface tension of water by members of the series, in solutions containing $1 \mathrm{mg}$./c.c. of each salt. With most of the compounds there was little depression of the normal surface tension of the water. With $\mathrm{C} 12$ and $\mathrm{C13}$, however, a distinct depression was observed, which became substantial with C18. Care was taken to control the time for which the surface was allowed to rest undisturbed before making a measurement, although the gradual fall of tension with time described for many surface-active substances was only observed with solutions of $\mathrm{C} 18$. The depression of tension recorded is therefore to some extent an arbitary one (measured after $10 \mathrm{~min}$. had elapsed from first creating the surface), but it appeared to be within 5-10 per cent of the maximum value. It follows from these observations that one cannot look to changes in surface activity to explain variations in pharmacological actions of members below. about $\mathrm{C} 12$.

\section{Species difference}

\section{Discussion}

One of the most remarkable properties of the members of this series, and especially of $\mathrm{C10}$, was the very great variation in their activity according to the species of animal on which they were tested. Such a variation is much smaller, and in the reverse sense, with $d$-tubocurarine chloride. Variation of this sort has been described for many other onium salts, but its magnitude for $\mathrm{C10}$, sufficient to make a compound of great activity in the cat appear to be of slight activity in the rat, possesses few parallels. The species variation in the sensitivity to histamine is, perhaps, the nearest to it, in that cats are relatively sensitive and mice and rats highly resistant. But this variation in sensitivity to histamine receives a possible explanation (Emmelin, 1945) in the respective plasma histamine levels of these animals: it is reasonable that those with plasmas rich in histamine should be resistant to it, since even cats can be accommodated to sustained histaminaemia. No such circulating onium salt has, however, yet been demonstrated, and we 
have obtained no evidence of adaptation to the effects of C10.

Although, then, there appears to be no ready explanation of the species variation, its practical importance deserves emphasis. Any investigation of new curarizing agents must necessarily be made with more than one species. Further, even with comparative assays of one substance, it may be necessary to establish that the dose-response relations do not vary with different species; and with assays of substances possibly containing several agents, it will be essential to be sure that all the test methods used are sensitive to all the agents involved. The properties of $\mathrm{C} 10$ are a strong justi- fication for including experiments on cats at an early stage in any investigation-particularly since later trials have shown that of all the species tested the cat most closely resembles man (Organe, Paton, and Zaimis, 1949).

\section{The antagonism of C5 and C6 to C10}

The characteristics of this antagonism may be briefly summarized as follows: it is a reversible antagonism to the action of one active compound displayed by a closely related but inactive homologue. These characteristics, and the other evidence we have presented, are typical of antagonism by competitive inhibition (cf. Woolley, 1947).

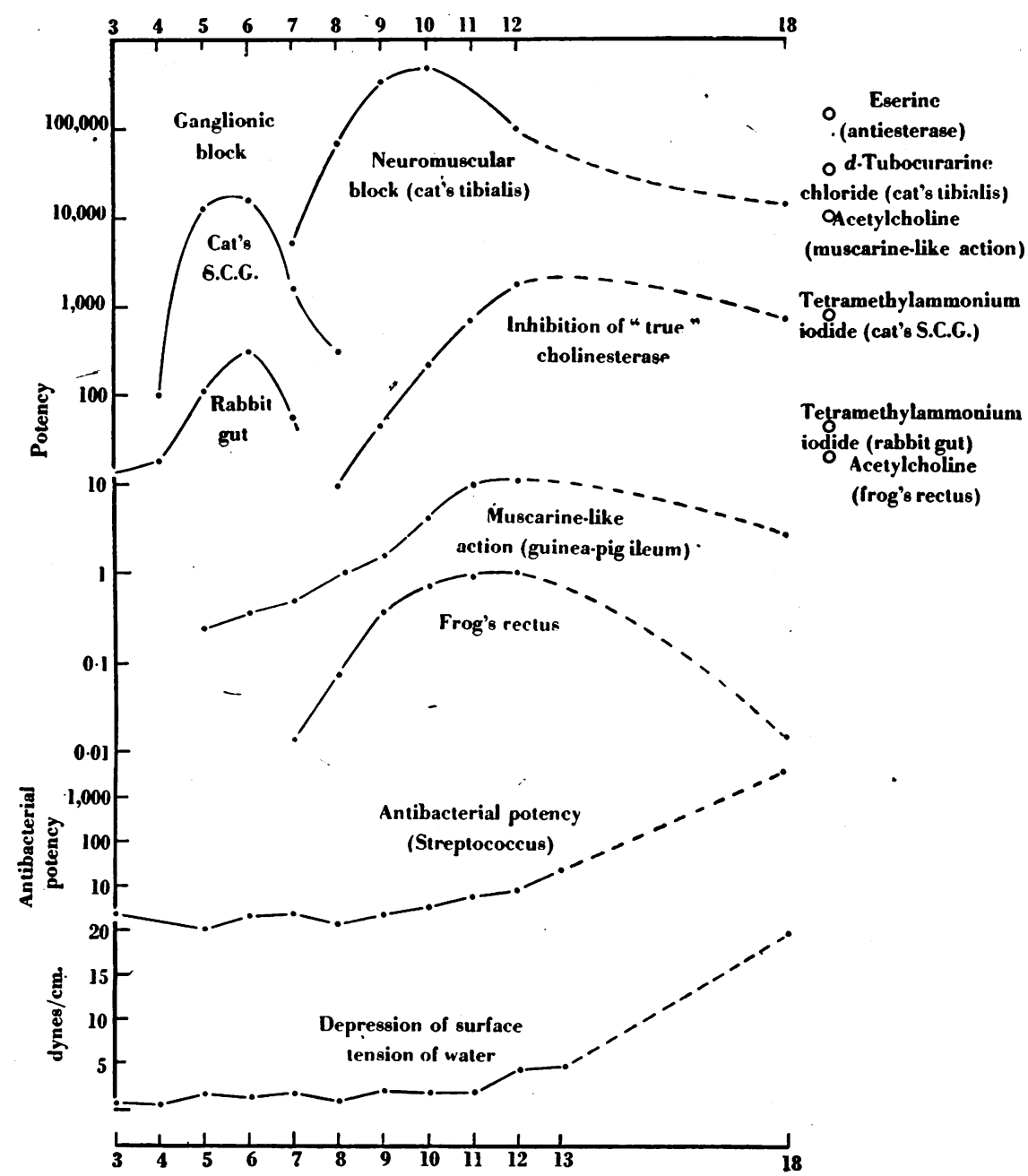

Fig. 17.-Summary of the main pharmacological actions of the bistrimethylammonium series. Abscissa: number of carbon atoms in polymethylene chain. Ordinate: logarithmic scale of potency, with arbitrary origins. 
For instance, the failure of $\mathrm{C5}$ to antagonize large doses of $\mathrm{C10}$ is readily explained as being due to inability to achieve a sufficiently high ratio of $\mathrm{C5}$ to $\mathrm{C10}$ for successful competition before $\mathrm{C} 5$ begins to depress neuromuscular conduction itself.

Although this type of antagonism is well known it appears to be a new phenomenon in the field of neuromuscular block. We have not analysed it in any detail. But, for reasons which will be clear from what follows, we do not believe that antagonists of this kind exist for most curarizing compounds, but only for those substances which produce neuromuscular block in the same way as $\mathrm{ClO}$.

\section{Relation between chemical structure and pharmaco- logical action}

We have collated the bulk of the material reported in this investigation in Fig. 17. All the main activities of the members of the series are there represented, relating their potency to their chain length. (There is no, particular significance in the position of the curve for any one activity on the potency scale, the origin on the scale of ordinates being quite arbitrary; but this scale is logarithmic, so that the slopes of the curves are comparable at all points.) Together with this are plotted the measurements of the depression of the surface tension of aqueous solutions of the compounds.

These results may be roughly summarized as showing three maxima for pharmacological activities: for ganglionic action at $\mathrm{C5}-\mathrm{C} 6$; for neuromuscular blocking action at $\mathrm{ClO}$; and a less well defined maximum for stimulation of frog's rectus, muscarine-like, and anticholinesterase activity around $\mathbf{C 1 2}$. These maxima are sufficiently distinct and striking to require separate discussion.

The easiest of these to explain is that in the region of $\mathrm{C12}$. We have, here, bisquaternary compounds of increasing chain length whose activities (muscarine-like and in stimulating frog's rectus) steadily approach those of the analogous monoquaternary salts (exemplified by tetramethylammonium ion). Such a tendency is not unexpected, and occurs in other connexions. Thus it has been observed with aliphatic diamines, $\mathrm{NH}_{2}\left(\mathrm{CH}_{2}\right)_{n} \mathrm{NH}_{2}$, that the shorter members $(n=6$ or 8$)$ are substrates of diamine oxidase, and the longer members $(n=14,16$, or 18) lose this activity but become instead substrates for mono-amine oxidase (Blaschko and Duthie, 1945). Again, MacIntosh and Paton (1949) found that the long-chain diamine with $n=16$ had a mixed pressor and depressor effect on the cat's blood pressure, characteristic both of the aliphatic monoamines and of the histamine-liberating diamines. On the other hand, as the chain length of these bisquaternary salts increases certain physical properties of the salts (which we have measured by their activity in depressing the surface tension of water) become more prominent. It is interesting that this surface activity begins to appear at $\mathrm{C12}$, the point at which increase in pharmacological activity on frog's rectus and guinea-pig's intestine almost ceases. We suggest, therefore, that this maximum near $\mathrm{C12}$ represents the balance-point between an increase in activity as the compounds approximate to an effectively monoquaternary state and a fall in activity as the hydrocarbon moiety of the molecule becomes large enough to influence the action of the compound.

The variations of antibacterial potency, reaching a maximum (so far as this series extended) at $\mathrm{Cl}$, obviously parallel directly the changes in surface activity. Similar examples, for instance among the alkyl resorcinols, are well recognized, and the relationship between surface activity and antibacterial potency is discussed by Work and Work (1948).

In quite a different category is the maximum at $\mathrm{C} 10$; this occurs at a point where changes in surface activity are not yet significant, although the rate of change of potency with chain-length is very rapid round the peak, especially in the C6-7-8 region: here alteration of chain length by one carbon atom causes a change in potency by a factor of about 20 times. It is of interest that approximately the same distance separates the nitrogen atoms in $\mathrm{C10}$ as in $d$-tubocurarine chloride and in Bovet's compounds (3381 R.P. and 3565 R.P.) despite the differences between $\mathrm{C10}$ and these substances. But it may be questioned whether this distance is specific for activity at the neuromuscular junction. Thus $n=10-11$ is optimal for histamine release by diamines (MacIntosh and Paton, 1949), and synthalin (diguanidinodecane) is the most active member of its series in causing hypoglycaemia.

The sharpness of the peak raises the question as to why the length of the polymethylene chain should be so critical, and certain comments may be made. First, $\mathrm{C} 10$ is at least 100 times more active in causing neuromuscular block than tetramethylammonium or trimethyldecylammonium salts (cf. Ing and Wright, 1931) ; it seems necessary to postulate therefore that both ends of $\mathrm{C10}$ are active, presumably (from the symmetry of the molecule) in the same way. Further, it is unlikely 
TABLE XIV

SYNOPSIS OF DIFFERENCES BETWEEN C10 AND $d$-TUBOCURARINE CHLORIDE

\begin{tabular}{|c|c|c|}
\hline & $\mathrm{C} 10$ & $d$-Tubocurarine chloride \\
\hline 1. Species sensitivity $\quad \ldots \quad \ldots$ & 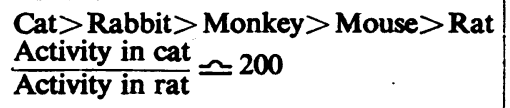 & $\begin{array}{l}\text { Rat }>\text { Mouse }>\text { Rabbit }>\text { Cat } \\
\text { Activity in cat } \\
\overline{\text { Activity in rat }} \cong 0.5\end{array}$ \\
\hline 2. Muscle selectivity & $\begin{array}{l}\text { Paralyses respiratory muscles less than } \\
\text { limb muscles in cat }\end{array}$ & $\begin{array}{l}\text { Paralyses respiratory muscles more } \\
\text { than limb muscles in cat }\end{array}$ \\
\hline $\begin{array}{l}\text { 3. Character of muscle response to } \\
\text { tetanic stimulation during block }\end{array}$ & Well-sustained contraction & Poorly sustained contraction \\
\hline $\begin{array}{l}\text { 4. Effect of } \mathrm{KCl} \text { or of a tetanus on } \\
\text { block }\end{array}$ & None & Decurarization \\
\hline 5. Effect of antiesterases on block & No antagonism & Decurarization \\
\hline 6. Effect of C5 on block ... & Antagonized & No antagonism \\
\hline 7. Effect on striated muscle & $\begin{array}{l}\text { Elicits contracture of frog's rectus } \\
\text { (and potentiates acetylcholine). } \\
\text { Elicits twitch of cat's tibialis }\end{array}$ & $\begin{array}{l}\text { Elicits no contraction of cat's tibialis } \\
\text { or of frog's rectus; antagonizes } \\
\text { acetylcholine on frog's rectus }\end{array}$ \\
\hline $\begin{array}{l}\text { 8. Effect of } d \text {-tubocurarine chlor- } \\
\text { ide administered previously }\end{array}$ & $\begin{array}{l}\text { Antagonized (both on cat's tibialis } \\
\text { and on frog's rectus) }\end{array}$ & $\begin{array}{l}\text { Potentiated. (Also potentiated by } \\
\text { C10 previously) }\end{array}$ \\
\hline 9. Effect of ether anaesthesia $\ldots$ & Antagonized & Potentiated \\
\hline $\begin{array}{l}\text { 10.Effect on demarcation potential } \\
\text { of tibialis muscle }\end{array}$ & Depressed & Not depressed \\
\hline
\end{tabular}

that the terminal groups ever approach each other to any great extent, since both carry strong positive charges. It is reasonable to suppose, therefore, that the molecule when active is extended on some cell-membrane. Finally, it is difficult to avoid the conclusion that the extreme sensitiveness of the activity of the series to chain-length implies some rather specific "fit" between the extenided molecule and its effector site. It is tempting then to suppose that the effective distance between the terminal groups (of the order of $10 \AA$, allowing for some freedom of movement of the chain) corresponds to the spacing of some regularly recurring receptor groups, or to the commonest inter-receptor distance in a random array of receptor groups. A recurrent acidic residue on a polypeptide chain would provide an array of the type required. Such a theory, indeed, explains the shape of the peak at $\mathrm{C10}$, with its rapid cut-off at $\mathrm{C} 6-\mathrm{C} 7$ and slower decline from $\mathrm{C} 12$ onwards ; for a chain less than the critical length would be entirely unable to straddle the required distance, although a longer chain would, occasionally at least, be able to adopt a configuration with its terminal groups sufficiently close.
Similar considerations apply, of course, to the peak for ganglionic activity ; but too little is known about such compounds to elaborate the argument. Other considerations and anomalies raised by the activities of $\mathrm{C} 5$ and $\mathrm{C} 6$ will be referred to in another paper. It is worth mentioning here, however, that $\mathrm{ClO}$ and $\mathrm{C5}-\mathrm{C} 6$ provide yet another and remarkable example of the dissociation of activities in neuromuscular and ganglionic block. A dose of $\mathrm{C10}$ more than a hundred times that adequate for neuromuscular block fails to paralyse the superior cervical ganglion; a dose of C5 more than a hundred times that adequate for ganglionic block fails to paralyse the neuromuscular junction.

\section{Mode of action of $\mathrm{ClO}$}

In the following discussion we shall refer only to $\mathrm{C10}$, since of the compounds studied it is the most active as a neuromuscular blocking agent ; but we have no reason to doubt, and much evidence to support the presumption, that its neighbours act in the same way. The experiments we have described demonstrate that $\mathrm{C} 10$ possesses those properties classically regarded as "curarizing." Like $d$-tubocurarine chloride, it paralyses neuromuscular transmission only, leaving nervous 
conduction unaltered, and permitting the muscle to respond to direct stimulation; it prevents the effect of a close arterial injection of acetylcholine ; it does not interfere with the release of acetylcholine. But apart from these resemblances, there are differences which we believe to be sufficiently important to enumerate in some detail (Table XIV).

These differences are more radical than those among, say, $d$-tubocurarine chloride, its methyl ether or other related alkaloids, and the compounds studied earlier by Bovet and his colleagues. Among these there occur variations in potency, in duration of action, in activity in releasing histamine, in ganglionic activity, or in antiesterase activity. But apart from these quantitative differences (which exist also between curare and C10) there appears no evidence that the modes of action of all these compounds differ fundamentally in any way. Their actions in causing neuromuscular block, like those of curare, fit conveniently into the theory that they act by competing with the acetylcholine liberated at the nerve terminals for effector sites on the motor end-plate.

This is not true for C10. Thus agents delaying the destruction of acetylcholine do not antagonize its action. (It might be suggested that this is so because $\mathrm{C} 10$ itself already partially inactivates the cholinesterase around the end-plate; but the weakness of $\mathrm{ClO}$ as an anticholinesterase, and the absence of any antagonistic action by $\mathrm{C} 10$ to that of $d$-tubocurarine chloride, make it unlikely that more than a small part of the cholinesterase concerned is inhibited by the doses of $\mathrm{C} 10$ used.) On the other hand; C5 is a successful antagonist, in a fashion strongly suggestive of a competitive inhibition. If $\mathrm{C} 10$ competes for effector sites with acetylcholine, and if $\mathrm{C} 5$ competes with $\mathrm{C} 10$ for the same sites, then C5 itself should be able to compete effectively with acetylcholine; and it should hence possess a blocking action at the junction when given in a dose effective in antagonizing $\mathrm{C} 10$; this in fact it lacks. Only by additional assumptions about the stability of various drug-effector complexes can the properties of $\mathrm{C5}$ be reconciled with a "competitive" theory of the action of C10. Another important difference lies in the ability of C10 to stimulate skeletal muscle, in concentrations little greater than those in which acetylcholine is effective. This, together with the fact that C5 is an antagonist to $\mathrm{C} 10$ both when stimulating muscle and when causing neuromuscular block, indicates that the role of $\mathrm{C} 10$ is not that of an inactive competitor with acetylcholine but that it is itself active in some respect at the neuromuscular junction.
We have described the way in which a muscle, in which partial block has been produced by $\mathrm{C10}$, characteristically sustains its response to tetanization of its motor nerve. It is equally characteristic of the partially curarized muscle that it cannot maintain a tetanic response. It is out of place to discuss fully this difference here ; it may, of course, be due to some peculiar property possessed by $d$-tubocurarine chloride which has not yet been revealed; but it also raises the possibility that the block produced by $\mathrm{ClO}$ is at some other part of the junctional system than that at which $d$-tubocurarine chloride produces block. The strange interaction between the two compounds suggests the same possibility. Whatever the explanation of the ability of $d$-tubocurarine chloride to antagonize $\mathrm{C} 10$, and of the inability of $\mathrm{C10}$ to do the same to $d$-tubocurarine chloride, it is difficult to account for these facts on the supposition that the two compounds block at the same point.

The arguments we have presented suggest, therefore, that $\mathrm{C} 10$ produces neuromuscular block by initiating some active response in the end-plate or muscle fibre; and that this block may arise at a part of the junctional system different from that blocked by $d$-tubocurarine chloride. An active response of the kind suggested has, indeed, been demonstrated, as a depolarization of the muscle fibre (Brown, Paton, and Vianna Dias, 1949) ; and this represents an additional distinction of $\mathrm{C} 10$ from curare which we have included in Table XIV. The relationship of this depolarization to the neuromuscular block remains, however, to be elucidated. We wish, at the moment, to do no more than draw attention to the striking differences between the two drugs, and to indicate the possibility of a fundamental divergence in their mode of action.

Finally, certain points may be mentioned concerning the differences in chemical structure which underlie the differences between "C10-like" and " $d$-tubocurarine-like" compounds. The information required to make a detailed comparison is not yet available. (For references, see Bovet et al., 1949 ; Paton, 1949). But one may take, as a rough guide, resistance to antiesterases and stimulation of frog's rectus to be typical of $\mathrm{C10}$; and sensitivity to antiesterases and antagonism to acetylcholine on frog's rectus abdominis to be typical of $d$-tubocurarine chloride. It then appears that, of the compounds so far adequately studied which cause neuromuscular block, only tetramethylammonium ion and its trimethyl-alkyl analogues, and succinylcholine (our experience with which agrees with that of Bovet et al., 1949) and its 
related aliphatic choline esters, resemble $\mathrm{C} 10$; the other compounds, including relatives of $d$-tubocurarine chloride, the erythroidines, and many of the compounds studied by Bovet and his colleagues, all resemble $d$-tubocurarine chloride. It is remarkable and suggestive that this division is also between aromatic compounds of widely variable structure on the one hand and, on the other, aliphatic compounds containing methyl-substituted quaternary nitrogen.

\section{SUMMARY}

1. The pharmacological properties of a series of polymethylene $\alpha$ - $\omega$ bistrimethylammonium iodides with. $2,3,4,5,6,7,8,9,10,11,12,13$, and 18 carbon atoms in the polymethylene chain have been studied.

2. The decane derivative (C10) causes neuromuscular block in the cat in doses of $30 \mu \mathrm{g} . / \mathrm{kg}$. intravenously, and is the most active member of the series in this respect. During such block, the excitability of nerve and muscle is retained, the effects of acetylcholine injected arterially are paralysed, and acetylcholine release by motor nerve terminals is not prevented. Tetanization of the motor nerve or injection of acetylcholine or potassium neither diminishes nor deepens the block. A phase of potentiation of the muscle twitch, fasciculations of the muscle, and repetitive responses to single nerve volleys precedes the block. During a partial block, tetanization of the muscle leads to a well-sugained contraction.

3. In the cat, profound neuromuscular block of the tibialis muscle may be caused by $\mathrm{C10}$, without paralysis of respiratory muscles. With $d$-tubocurarine chloride respiratory paralysis accompanies or may precede paralysis of tibialis.

4. C10 is $50-100$ times less active by mouth than by intravenous injection. Its activity in cats anaesthetized with chloralose or pentothal is similar to that in the unanaesthetized cat ; but ether appears to antagonize it slightly.

5. Sensitivity to $\mathrm{C} 10$ varies greatly with species : in order of decreasing sensitivity, the series is catman - rabbit - monkey - mouse - rat. For $d$-tubocurarine chloride by the same tests, the variation in sensitivity is much smaller and decreases: ratmouse-rabbit-cat.

6. The action of $\mathrm{C} 10$ is not antagonized by anticholinesterases. The pentane and hexane homologues (C5, C6) are effective antagonists; the antagonism appears to be by competitive inhibition. Previous administration of $d$-tubocurarine chloride also reduces the effectiveness of $\mathrm{C} 10$.
7. $\mathrm{C} 10$ and its neighbours elicit a contracture of the frog's rectus abdominis muscle, and do not antagonize the contracture elicited by acetylcholine. C5 and C6 do not elicit such a contracture, but antagonize the actions both of $\mathrm{C10}$ and of acetylcholine. C10 can also elicit a twitch of cat's tibialis muscle if a small dose is given by close arterial injection.

8. Members of the series, particularly $\mathrm{C5}$ and C6, are able to block ganglionic transmission. Higher members possess a weak anticholinesterase action, which is more active against " true " cholinesterase than against "pseudo" cholinesterase. They also possess a weak muscarine-like action, a weak power of releasing histamine, and a feeble antibacterial action. No significant atropine-like action, or ability to stimulate autonomic ganglia, was detected. With the exception of $\mathrm{C} 18$, members of the series display negligible activity in depressing the surface tension of water.

9. The pharmacological properties of the series have been related to the length of the polymethylene chain. This reveals four features: (1) a sharp maximum for potency in ganglionic block at C5-C6; (2) a sharp maximum for potency in neuromuscular block at $\mathrm{ClO}$; (3) a less well-defined maximum for muscarine-like activity, stimulation of frog's rectus, and anticholinesterase activity about $\mathrm{C} 12$; (4) a rise in antibacterial activity and surface activity beginning about $\mathrm{C12}$ and still increasing at $\mathrm{C} 18$.

10. The significance of the species difference, of the competitve antagonism of C5 for $\mathrm{C10}$, of the variation of activity with length of polymethylene chain, and of the differences between $\mathrm{C} 10$ and $d$-tubocurarine chloride is discussed.

It is a pleasure to express our indebtedness to Dr. Harold King for his interest and guidance throughout this investigation, and to our colleagues for many fruitful discussions and criticisms.

We are also indebted to Dr. T. S. Work for advice on determining anticholinesterase activity, to Miss Bashford for assistance in these determinations, and to Dr. J. Niven for the histological examinations.

\section{REFERENCES}

Bacq, Z. M., and Brown, G. L. (1937). J. Physiol., 81, 45. Barger, G., and Dale, H. H. (1910). J. Physiol., 41, 19. Barlow, R. B., and Ing, H. R. (1948a). Nature, Lond., 161, 718.

Barlow, R. B., and Ing, H. R.(1948b). Brit.J. Pharmacol., 3, 298.

Blaschko, H., and Duthie, R. (1945). Biochem. J., 39, 478.

Bovet, D., Bovet-Nitti, F., Guarino, S., Longo, V. G., and Marotta, M. (1949). Rendiconti Instituto Superiore di Sanita, 12, 106. 
Briscoe, G. (1936). Lancet, 1, 469.

Brown, G. L. (1937). J. Physiol., 89, 438.

Brown, G. L. (1938a). J. Physiol., 92, 22P.

Brown, G. L. (1948b). J. Physiol., 92, 23P.

Brown; G. L., Burns, B. D., and Feldberg, W. (1948). J. Physiol., 107, 346.

Brown, G. L., Paton, W. D. M., and Vianna Dias, M. (1949). J. Physiol, 109, 15 P.

Dutta, N. K., and MacIntosh, F. C. (1949). (In press.)-

Emmelin, N. (1945). Acta physiol. scand., 11, Suppl. 34.

Eeldberg, W., and Lin, C. Y. (1949). Brit. J. Pharmacol., $4,33$.

Harvey, A. M. (1939). Bull. Johns Hopk. Hosp., 65, 223.

Ing, H. R., and Wright, W. M. (1931). Proc. Roy. Soc., B., 109, 337.

King, H. (1935). J. chem. Soc., 1381.

MacIntosh, F. C., and Paton, W. D. M. (1949). J. Physiol., 109, 190.
Organe, G., Paton, W. D. M., and Zaimis, Eleanor J. (1949). Lancet, 1, 1.

Paton, W. D. M. (1949a). J. Physiol., 108, 57 P.

Paton, W. D. M. (1949b). J. Pharm. Pharmacol., 1, 273.

Paton, W. D. M., and Zaimis, E. J. (1948a). Nature, Lond., 161, 718.

Paton, W. D. M., and Zaimis, E. J. (1948b). Nature, Lond., 162, 810.

Rosenblueth, A., Lindsley, B. D., and Morison, R. S. (1936). Amer. J. Physiol., 115, 53.

Wilson, A. T., and Wright, S. (1936). Quart. J. exp. Physiol., 26, 127.

Woolley, D. W. (1947). Physiol. Rev., 27, 308.

Work, T. S., and Work, E. (1948). The Basis of Chemotherapy. London: Oliver and Boyd.

aimis, E. J. (1949). J. Physiol., 109, Proceedings, July 1-2. 